\title{
Pedagogia freireana como método de prevenção de doenças
}

\author{
Freire's pedagogy as a method to prevent diseases
}

Eveline Pinheiro Beserra ${ }^{1}$

CibeleAlmeida Torres ${ }^{1}$

Patrícia N eyva Costa Pinheiro ${ }^{1}$

M aria Dalva Santos Alves ${ }^{1}$

M aria Grasiela Teixeira Barroso ${ }^{1}$

${ }^{1}$ Centro de Ciências da

Saúde. UniversidadeFederal do Ceará. RuaAlexandrede

Baraúna 1.115, Rodolfo

Teófilo. 60430-160

Fortaleza CE.

eve_pinheiro@yahoo.com.br
Abstract The actions of health promotion directed to adolescents must consider sexual and reproductive health, taking into account doubts on the approached theme. It is a qualitative re search which aims to investigate sexuality in male adolescents with the implementation of the circle of culture as an educative action in the prevention of sexually transmitted diseases. It was carried out in a public school in Fortaleza, Ceará State, with 10 boys aged from 14 to 16 years old in the period between August and November, 2007. It was adopted the circle of culture, Freire's dialogical pedagogy, as methodological route. It was observed that boys associate sex to sexuality predominantly and that they have little comprehension of the vulnerabilities which they are exposed to in an unprotected sexual intercourse, once they demonstrated they wereincentivated precociously to begin their sexual life, many times without previous reflection on the possible consequences. It was evinced the necessity of educative actions, such as the circle of culture, which offer youngsters the opportunity to show their doubts and to know means to prevent sexually transmitted diseases. It also makes them able to rethink behaviors with the objective of reaching a better life quality in their sexuality.

Key words Health education, Adolescence, Sexually transmitted diseases
Resumo Asações depromoção da saúdevoltadas para o grupo de adolescentes devem contemplar a saúde sexual ereprodutiva, levando em consideração as dúvidas acerca da temática abordada. Trata-se de uma pesquisa qualitativa, com o objetivo deinvestigar a sexualidade deadolescentes do sexo masculino com a implementação do círculo de cultura como ação educativa na prevenção de doenças sexualmente transmissíveis. Foi realizada numa escola pública em Fortaleza (CE), com dez meninos entre catorze e dezesseis anos, no período deagosto a novembro de 2007. A dotou-seo círculo de cultura, pedagogia freireana dialógica, como percurso metodológico. O bservou-se que os meninos associam o sexo à sexualidade de forma predominante e que tinham pouca compreensão das vulnerabilidades a que estavam expostos numa prática sexual desprotegida, uma vez quedemonstraram ser incentivados precocemente ao início da vida sexual, muitas vezessem reflexão prévia de suas possíveis consequências. Evidenciou-se a necessidade de ações educativas, como o círculo de cultura, que propiciam ao jovem expor suas dúvidas e conhecer os meios de prevenção das doenças sexualmente transmissíveis, como também capacitá-los a repensar condutas a fim de alcançar meIhor qualidade de vida em sua sexualidade. Palavras-chave Educação em saúde, Adolescência, D oenças sexualmente transmissíveis 


\section{Introdução}

A educação em saúde visa contemplar os princípios do SistemaÚ nico de Saúde(SUS) por intermédio da promoção da saúde e da conscientização do indivíduo e da comunidade em procurar a garantia de seus direitos. Dessa forma, a articulação de meios que correlacionem educação e saúde, a fim de proporcionar mudança de comportamento do indivíduo, favorece a isenção de riscos que 0 impossibilitem de viver saudavelmente ${ }^{1}$.

Nestecontexto devulnerabilidade, a juventude destaca-se por ser uma etapa de vida delicada, no que diz respeito a sua orientação de condutas, necessitando que muitos temas sejam abordados, como a sexualidade, uma vez que, em sua maioria, os jovens são imaturos e alguns deles buscam aventuras, ignorando a possibilidade de se contaminarem com alguma das doenças sexualmente transmissíveis (DST), ou até mesmo acreditam que realizam 0 ato sexual com pessoas seguras, isentas de al guma doença transmissível, enquanto, na verdade, todos estão susceptíveis à contaminação?

Especificamentesobreas DST/HIV/aids, houve significativo aumento da infecção pelo HIV. No mundo, das trinta milhões de pessoas infectadas pelo HIV, pelo menos um terço tem entre dez e 24 anos. No Brasil, 11,4\% dos casos diagnosticados entre 1980 e2006 foram em jovens de treze 24 anos $^{3}$. A vulnerabilidadena adolescência, com relação à sexualidade, é confirmada quando se percebe que os casos de aids aumentam nesta fase, também, destacando a questão de gênero, atrelada a esse contexto.

Em razão da necessidade de inserir a promoção da saúde em todos os contextos, cabe aos profissionais da saúde a sensibilização para que se possa trabalhar com esse objetivo, promover saúde, contemplando as especificidades da adolescência. A respeito da iniciação sexual, muitos jovens percebem a juventude como uma etapa em que se goza a liberdade de experimentar o prazer de viver; logo, nota-se a necessidade de intervenções educativas junto a esse grupo ${ }^{4}$.

A enfermagem, intimamente ligada ao ser humano e preocupada com o seu bem-estar e sua qualidade de vida, enquadra-se no desafio de ações em educação em saúde que permitam incentivar os jovens à reflexão crítica de sua realidade, como também discutir habilidades para trabal har estratégias de educação em saúde, voltadas para atividades que propiciem a conscientização de adolescentes para a preven ção das DST.
Uma das estratégias de educação que pode ser utilizada éo círculo de cultura, um método de Paulo Freire, queécapaz deestabelecer o diálogo e a discussão sobre diversos temas, capacitando as pessoas a refletirem sobre sua realidade.

Desta forma, este estudo teve como objetivo investigar a sexualidade de adolescentes do sexo masculino, com base na implementação do círculo de cultura na prevenção de doenças sexualmentetransmissíveis, realizando um levantamento das necessidades educativas em adolescentes sobre essa temática.

\section{M etodologia}

Trata-se de um estudo qualitativo exploratório, realizado numa escola de ensino fundamental e médio em Fortaleza (CE). 0 número de participantes foi intencional para contemplar o objetivo do estudo, totalizando dez meninos escolhidos al eatoriamente, entre catorzee dezesseis anos, do quinto ano do ensino fundamental, que obe deceram aos seguintes critérios deinclusão: estarem devidamente matriculados na escola e desejarem participar da pesquisa.

0 período da investigação foi de agosto a novembro de2007. 0 presenteensaio usou como instrumentos e procedimentos a observação, observação participante, diário de campo e círculo de cultura. Este foi empregado para promover educação em saúde, pois se trata de uma metodologia que permite aos adolescentes dialogar abertamente sobre sua vida5. 0 círculo de cultura favorece 0 aprendizado rápido, contextualizado à realidade dos educandos, existindo uma inter-relação que proporciona liberdade e crítica acerca do assunto abordado, resultando em um grupo mais participativo nos debates, diálogos e trabalhos, como também é utilizado como um itinerário de pesquisa ${ }^{6}$.

O círculo de cultura foi composto por cinco encontros, nomeados como diálogos, com duração de cinquenta minutos, abordando os seguintes temas: adolescência, sexualidade, doenças sexualmente transmissíveis, vida sexual segura e uso do preservativo. 0 primeiro diálogo foi constituído por palavras geradoras, que são ditas pelos próprios participantes do grupo. Essas palavras significam o contexto real no qual os educandos vivem, sendo essenciais para a condução do círculo de cultura e realização dos encontros posteriores, como também para a elaboração das fichas de cultura. 0 segundo diálogo foi a integração das palavras geradoras, quan- 
do se dialogou acerca de temas do interesse dos jovens; o terceiro relatou a abordagem das doenças sexualmente transmissíveis, enquanto 0 quarto cobriu discussões diversas, em que foram refletidas a saúde sexual e reprodutiva dos adolescentes. Por fim, o quinto diálogo foi a avaliação do processo. 0 círculo foi composto também por um animador, que mediava as discussões, organizava e coordenava o grupo, de modo a proporcionar a participação dos educandos durante os diálogos 6 .

Para a análise dos dados deste estudo, utilizou-sea análise de conteúdo de Bardin, uma técnica que analisa as comunicações, objetivando reconhecer indicadores que permitam a aquisição de conhecimentos relativos às condições de produção e recepção destas mensagens, através deprocedimentos sistemáticos eobjetivos dedescrição do conteúdo das mensagens ${ }^{7}$.

Foram respeitados os aspectos legais e éticos que envolvem pesquisas com seres humanos, conforme a Resolução no 196/96 do Conselho Nacional de Saúde. Também foi esclarecido aos jovens que a recusa em participar da pesquisa não Ihe causaria nenhum prejuízo ao acesso à escola pesquisada. Foi assinado o termo de consentimento livre e esclarecido, tanto pelos adolescentes como pelos responsáveis. Ressalta-se que o estudo foi submetido à apreciação do Comitê de Ética em Pesquisa da Universidade Federal do Ceará e aprovado na reunião do dia 26 de julho de 2007 e, somente após autorização, deuse seu início ao ensaio.

\section{Resultados ediscussões}

A escola é um local de troca mútua, em que professores e alunos se integram, a fim de construírem o conhecimento. A educação escolar está relacionada ao trabalho dos professores e dos alunos, tendo como finalidade o caráter coletivo e interdisciplinar para alcançar o saber. É possível oferecer aos adolescentes o pensamento crítico desua condição de vida ede seu processo deadolescer por meio do diálogo.

\section{Primeiro diálogo}

Essa oficina tem como princípio a primeira integração com os participantes do grupo por meio do acolhimento. As cadeiras estavam em forma de círculo com o propósito de favorecer essa integração.
No início do grupo, foi realizada a reflexão: "O que vem na mente do jovem à associação adolescência e sexualidade?", surgindo, então: masturbação, sexo, tesão, doenças, camisinha, proteção, atração e prazer. Os meninos relataram uma ação própria da descoberta do corpo, a masturbação, como também enfatizaram a relação sexual como sexualidade, porém não falaram sobre gravidez, levando a que ocorra o repasse para o sexo feminino, isto é, a responsabilidade da gestação.

Deforma dialógica, refletiu-secomo o jovem percebe sua sexualidade, e alguns responderam: "o tesão pelas meninas", "a primeira vez", "a primeira transa", "a voz mudando", "os cabelos nascendo", "uns são criança com molecagem".

Viu-se, com efeito, que o grupo não se deteve apenas ao ato sexual, pois conversou também sobre as alterações físicas e comportamentos que retratam a sexualidade. Observou-se que, em um dos comentários, foi relatado que o jovem não demonstra logo o seu amadurecimento afetivo, pois muitas vezes realiza ações infantis. Sobre as palavras "tesão" e "prazer", estas retratam a busca pelo prazer como ação de felicidade para o adolescente, como também a descoberta do novo8.

Sobre a reflexão de como a família percebe o jovem, foi dito: "percebe pela mudança do corpo, na voz. A família libera tudo para o homem epara mulher étudo diferente, ela é mais presa".

$\mathrm{N}$ a sociedade atual, o modo de educar as me ninas difere dos meninos em relação à sexualidade, direcionando mais liberdade para o sexo masculino, privando o sexo feminino de desfrutar de sua sexualidade igualmente. Os papeis desempenhados pelos jovens caracterizam-se pelo modelo de dominação de gênero, cuja visão de masculinidadee feminilidade dificulta o avanço de programas de promoção da saúde 8 . Os meninos relataram que conversam abertamente sobre sexo com a mãe ou com o pai, esclarecendo dúvidas, bem como pedindo conselho, consoante ao comentário: "Quando eu gosto de uma menina, eu falo para minha mãe, aí ela fala alguma coisa".

A abertura do jovem na família, sentindo-se à vontade para conversar sobre sexo, estabelece uma relação aberta, o que proporciona a liberdade para expor o assunto, numa suposição imaginária, como: "Se sua namorada estivesse com a menstruação atrasada, o que você faria?" Os jovens afirmaram: "Eu falaria com minha mãe, porque ela ia dar uma solução".

É possível uma relação aberta entre os pais eos adolescentes mediante 0 diál ogo, 0 que permite 0 reconhecimento de dúvidas e de situações vividas 
pelosjovens. Eles relataram queconversariam com os pais numa situação como a descrita, pois se sentem seguros. A relação de confiança deveexistir entre pais e filhos, não restringir apenas aos do sexo masculino. Os pais podem fazer parte da aprendizagem do jovem, havendo, possivelmente, a confiança mútua passível de ser estabelecida9.

Inseriu-se no diálogo a relação dos jovens com os amigos, surgindo o relato: "Esse povo é cabueta". Vale ressaltar que estudar um grupo é analisar também sua questão cultural e depararse com termos próprios de pessoas do seu vínculo social ecomumente ditas entre eles, como é o caso da palavra "cabueta". A cultura mostra a visão do mundo dos indivíduos, sendo necessário seu entendimento para queo educador possa intervir deforma pertinentena realidadedos educandos ${ }^{10}$. A frase, dita pelo jovem, significa que não pode confiar em amigos, porque eles contam para outras pessoas, na linguagem dos jovens do grupo, "eles saem espalhando".

$\mathrm{N}$ a discussão de como a escola percebe a sexualidade, foi relatado: "Não vê, não explicam nada sobre isso. Nunca tive aula sobre isso". Eles demonstram que a escola não orienta sobre sexualidade de forma aberta, deixando-os com questionamentos. A escola, a sociedade e a família têm, de modo geral, pouca compreensão dessa realidade de emoções dos jovens, uma vez que não sabem a forma de lidar com o tema ${ }^{9}$.

Os adolescentes querem conhecer as alterações do corpo, entender a mudança de comportamento, experimentar o novo; enfim, viver essa idade intensamente, mas, para que isso ocorra, torna-se necessário orientá-los a fim de que possam vivenciar deforma segura, sem risco decontaminação com alguma DST.

\section{Segundo diálogo}

No segundo momento, foram organizadas novamente as cadeiras em círculo e apresentadas as fichas de cultura. Estas sugerem um debate com suporte em figuras de situações da realidade do grupo, estimulando os educandos a pensar no seu mundo real e criticá-lo pelo diálogo. Vale salientar que as fichas foram elaboradas a partir das palavras geradoras ${ }^{6}$. Por meio das fichas de cultura, $\mathrm{O}$ animador medeia as discussões. $\mathrm{Na}$ primeira ficha decultura, havia um casal abraçado; na segunda, duas crianças iniciando um beijo; na terceira, a foto de um casamento; a quarta, por sua vez, continha uma adolescente grávida. No primeiro diálogo com o grupo, observou-se a correlação da sexual idade com a relação a dois, por isso que essas fichas retratavam, predominantemente, casais.

Em relação à ficha de cultura que retratava um casal, foi dito: carinho, amor, namoro, felicidade, "fica", "casquinha". Assim, foram permeados assuntos que compreendiam um relacionamento a dois. Questionou-se o conceito de "fica" para o grupo de meninos, relatado como " $U \mathrm{~m}$ momento com a menina, sem compromisso". Completaram seu comentário afirmando que pode ficar somente no beijo e abraço, como pode se estender ao ato sexual. Assim, percebem-se os ris$\cos$ a que estão expostos os meninos ao realizarem o ato sexual sem reflexão sobre o sexo seguro e a possibilidade da multiplicidade de parceiros.

Diante da figura de duas crianças namorando, os meninos relataram: "Só o que tem, os pive tes namorando". Eles têm a percepção dessa precocidade e mostraram isso com naturalidade. A questão da precocidade está visível socialmente, declarada para todos como um problema de saúde pública e de intervenção direta. 0 diálogo é uma das formas de educar e o círculo de cultura favoreceu a ação, mas, primeiramente, fez-se necessário conhecer as especificidades do grupo para, posteriormente, se intervir de maneira eficaz.

As discussões permearam o assunto do início da vida sexual. Os meninos falaram: "Na primeira oportunidade. Com primeira namorada". Diante desses comentários, eles demonstraram que qualquer momento pode ser o início da vida sexual, até mesmo sem orientação, nem instrução, nem reflexão. Esse ponto é imposto pela sociedade como forma de mostrar a masculinidade e que são sexualmente ativos, devendo a garota ser passiva, dependente e sensível ${ }^{8}$. Complementado esse fato, discutiu-secomo acontece a primeira relação sem orientação: “O rientação é a gente quefaz, deixa pra pensar na hora".

É enfática a discussão acerca de como a sociedade e a própria família expõem o filho como vulnerável a alguma DST ou à paternidade, por incentivá-lo a ser sexualmente ativo como demonstração de masculinidade, tornando-se de caráter urgente orientar com antecedência o jovem sobre os riscos de uma relação sexual desprotegida.

Relataram que a primeira relação pode ser a qualquer momento, dependendo daoportunidade e que a orientação, muitas vezes, eles "fazem" na hora. Sehá o incentivo para o ato sexual, que haja informações corretas sobre sexo seguro.

Antes da ficha de cultura que abria a discussão sobrea gravidez precoce, não houvenenhum 
relato dos meninos sobre esse assunto. Assim, esta ficha de cultura proporcionou uma reflexão sobre esse tema. Então, discutiu-se sobre a re percussão para o jovem que assume um filho, como deixar o estudo para trabalhar, o perigo do aborto, a perda da juventude, etc. Foi enfatizado o fato de que os dois têm responsabilidades por uma gravidez não planejada; porém, percebeu-se que os jovens não se preocupam com a gestação e demonstraram iniciar a vida sexual sem orientações sólidas sobre os métodos de prevenção deDST egravidez.

$\mathrm{Na}$ discussão sobre casamento, iniciado pela ficha de cultura que continha a foto de um casal, foi evidenciado o seguinte comentário: "hoje a galera só quer é curtição".

Essa fala retrata a banalização dos relacionamentos estáveis, percebendo a relação homem e mulher no casamento, a presença da traição, em que "ninguém éde ninguém" ea separação como algo comum na atualidade, havendo, assim, 0 maior risco para a multiplicidade de parceiros.

Durante todo o diálogo, enfatizou-se a reflexão sobre a importância de uma relação sexual segura econsciente, pois as consequências deuma relação desprevenida repercutem no aumento da suscetibilidade, tanto para a aquisição de alguma DST, quanto para uma gravidez precoce.

\section{Terceiro diálogo}

Houve discussão sobre a existência das DST. As fichas de cultura retratavam suas lesões. Então, abordou-se papiloma vírus humano (HPV), sífilis, gonorréia, herpes, como também se discutiu sobre a síndrome da imunodeficiência humana (aids). Enfatizaram-se os métodos de prevenção, as sintomatologias e a evolução dessas patologias.

Os meninos, durante a discussão sobre essas doenças, mantiveram-se mais atentos e menos participativos. 0 grupo de meninos foi conduzido pelo conceito de DST e enfatizou-se o sexo seguro com o uso do preservativo em todas as relações, como também foi discutido sobre 0 acondicionamento da camisinha.

Ao se conversar sobre o uso do preservativo, um jovem afirmou: "Eu tenho é muita, aqui, na carteira". Correlacionando esse diálogo com a afirmação relatada no diálogo anterior, de que a qualquer hora pode haver uma relação, observou-se haver jovens que andam com o preservativo na carteira e outros não. Faz-se necessário orientá-los sobre a prevenção das DST por meio de informações sobre a forma correta de colocar, retirar edescartar o preservativo para seisentarem de riscos e se tornarem multiplicadores dessas ações. Em relação ao acondicionamento do preservativo, discutiu-se sua maneira correta de preservá-lo, com a leitura da embalagem da camisinha que continha essas informações. A forma correta de armazená-lo precisa ser esclarecida, pois, muitas vezes, o preservativo encontra-se na carteira e com a embalagem amassada. Com respeito a este fato, o M inistério da Saúde veicula campanhas demonstrativas da importância do uso, bem como do armazenamento adequado de preservativos, porém não se restringe somente a isso, mas também orienta acerca do uso consciente, considerada a principal estraté gia de prevenção das DST ${ }^{11}$.

Vale salientar que a prática educativa foi preponderante, tendo como finalidadediscutir entre os jovens acerca dessa temática, para que eles se tornem reflexivos equestionadores desuas ações.

Ao término desse diálogo, foram distribuídas camisinhas e intensificada a noção de que seu uso énecessário em toda relação sexual eque pessoas conhecidas não são pessoas seguras para praticar 0 ato sexual sem preservativo, sendo segura a relação com camisinha.

\section{Quarto diálogo}

Esse encontro foi organizado considerando-seas necessidades específicas do grupo demeninos que foram surgindo no desenvolver do círculo de cultura. As discussões entre os meninos foram relacionadas à prevenção de DST em todas as relações sexuais, pois, nas primeiras oficinas, demonstraram que a qualquer momento poderiam ter uma relação, até mesmo sem camisinha. Retornando a essa questão, foi comentado: "A menina pede para fazer sem camisinha e, na hora da gente gozar, tirar. Eu tava na paredeamaciando a menina, quando eu fui ver, já tava lá". Diante dos comentários, é importante que o jovem perceba 0 ato sexual não só com risco de gravidez, mas também como um ato que pode propiciar a contaminação por alguma DST. A negociação do preservativo precisa ocorrer entre o casal, para que haja o sexo seguro, embora estudos mostrem que nem sempre o preservativo é utilizado pelos meninos quando mantêm relações sexuais com "ficantes"12. Assim, mesmo com as discussões sobre o risco de contágio das DST, alguns jovens não se acham vulneráveis, pois a sociedade impõe machismo e eles devem ser ativos em 
qualquer situação, mesmo quando não têm em posse o preservativo: "Se eu tiver oportunidade com uma menina e não tiver camisinha, eu faço, não tenho como negar".

0 trabalho com os meninos deve ser mais intensificado na prevenção de DST, pois muitos crescem em um ambiente no qual são cobradas dele uma namorada, uma relação sexual, para confirmar sua masculinidade. Observa-se a presença da legitimação de uma "natureza" muito mais sexual do homem, como há também o entendimento e a crença em uma "natureza" masculina, determinada pela necessidade do sexo, pelo instinto animal "incontrolável", sendo muito difícil para o homem "negar fogo", quando éabordado por mulheres, primeiro, porque ele "é homem"13. Assim, é recomendável que as estratégias de intervenção promovam a integração deconteúdos e ações de prevenção das DST e de atenção à saúde sexual e reprodutiva para os adolescentes, que têm grande parte dos encontros sexuais sem qualquer proteção $0^{14}$.

Dessa forma, reforçaram-se as discussões sobre todos os assuntos dos diálogos anteriores, no trabal ho de repetição, para que esses jovens, que não se sensibilizaram com a importância do uso do preservativo para preven ção de DST, possam refletir sobre suas condutas de vida. Também foi incentivado o uso do preservativo, sua aquisição no posto, pois os postos de saúde possuem camisinhas específicas com menor diâme tro para adolescentes.

É necessário reforçar a necessidade de investimentos na educação do contingente populacional jovem em geral, principalmente no que se refereà formação cidadã, capacitando-o a lutar pelos seus direitos, entre os quais o acesso a informações ne cessárias para a prática da anticoncepção ${ }^{15,16}$.

\section{Quinto diálogo}

Esta oficina estava relacionada à avaliação dos jovens em relação ao círculo de cultura, pois este foi realizado por eles. Assim, são os seus participantes os principais avaliadores de sua implementação. Durante o processo avaliativo, os jovens estavam livres para relatar o que quisessem sobreo círculo decultura, podendo ser o que eles tinham aprendido e/ou do que eles tinham gostado. Seus comentários foram categorizados em três aspectos: aprendizagem, assuntos e maneira de abordagem.

$\mathrm{Na}$ primeira, aprendizagem, havia relatos sobre a necessidade de refletir antes de iniciar a vida sexual eo conceito de sexo seguro. Também relataram sobreDST eo modo de prevenção destas com o uso da camisinha. Esta categoria mostrou que os adolescentes assimilaram a importância do uso do preservativo em todas as relações, mostrando assim a caracterização do círculo em promover educação em saúde, capacitando-os a refletir sobre suas condutas: "A prendi muitas coisas, como fazer sexo seguro, usando sempre camisinha e pensar antes de ter qualquer relação sexual com outra pessoa. A prendi mais sobre HIV e sobre a transmissão e como e quando a pessoa estará preparada para primeira relação. É através do sexo sem camisinha e não tem essa se eu conheço faz tempo é seguro, sempre fazer sexo com camisinha seja quem for".

$\mathrm{Na}$ segunda categoria, assuntos, eles relataram os temas abordados de que gostaram durante as oficinas, como as vulnerabilidades em relação às DST/aids, as maneiras de prevenção dessas doenças, o uso da camisinha e, também, as explicações, mais intensificadas para evitar 0 contágio por essas doenças que são passíveis de prevenção. Trata-se, com efeito, que eles perceberam a importância do tema, como também a sua necessidade de apren der e refletir sobre esses riscos que existem em sua juventude: "Q ualquer pessoa pode pegar aids através do sexo sem camisinha. Gostei dos encontros e como se proteger das doenças. Foi se proteger das DST e também que toda hora que a gente for fazer sexo, sempre usar camisinha. 0 que eu mais gostei nos encontros foi o alerta para nós não nos contaminarmos com essas doenças horríveis".

No ensejo da discussão da última categoria, maneira de abordagem, os adolescentes comentaram que gostaram de como o animador, nos comentários, identificado como professora, mediava as discussões, pois estas se caracterizaram de forma dialógica, abrindo espaço para que os participantes do grupo interagissem nas discussões por meio dos temas suscitados pelos jovens, que os incentivaram a repensar seus conceitos: "Eu gostei da maneira quea professora ensina a se prevenir das doenças. 0 que mais gostei foi 0 jeito quea professora ensinava".

Estas três categorias se completam, pois os assuntos foram do interesse dos jovens. A maneira de abordagem foi dialógica, para que eles se tornassem participativos nas discussões e, por fim, a aprendizagem, quefoi consequência natural dos encontros, já que a reflexão crítica realizada pelos adolescentes foi a partir dos temas relacionados a aspectos de sua juventude, abordados nas oficinas do círculo de cultura. 


\section{Considerações finais}

Nesse contexto, o círculo de cultura assume a importância de ser um meio efetivo para exercer ações de educação em saúde sobre a sexualidade ea prevenção deDST com adolescentes, com origem nas necessidades do grupo e, em seguida, capacitando-os às suas potencialidades em reconhecer situações de riscos que prejudicam sua qualidade de vida, bem como levá-los à reflexão sobre suas condutas.

Assim, é crucial se atentar, nessa implementação, para as necessidades específicas do grupo masculino, onde há, de um lado, a família, de outro, a sociedade, impondo que ele tenha um comportamento de "garanhão", sendo negligenciadas orientações no que se refere à sexualidade e aos meios de prevenção das DST.

Do primeiro ao último encontro do círculo decultura, foi possível identificar o conhecimento de como os adolescentes, a família, a escola e os amigos percebem a sexualidade do jovem, constatando-se a necessidade de intervir junto a esse grupo, considerando-se suas necessidades específicas. Conscientizou-se, pois, da necessida- dedeinterven ção, pois os meninos, sendo incentivados à vida sexual, expõem-se a risco de contágio por alguma DST, logo, cabendo repensar políticas de educação que favoreçam esclarecer os meios de prevenção dessas enfermidades.

Por ter sido o círculo de cultura conduzido, prioritariamente, pelos próprios participantes, os assuntos dialogados foram decididos por eles em concordância com o animador, tendo suas colocações apontado as idéias do que deveria ser discutido por meio das fichas de cultura, pois o grupo tinha condução própria, mas sempre o animador teveo papel de incentivá-los a discutir sobre métodos de prevenção, por meio de uma reflexão crítica de seus hábitos de vida. Observouse como é importante o aprendizado emergir do próprio grupo, pois eles se percebem no seu contexto e podem refletir sobre a própria realidade.

Constatou-se, com este estudo, que são necessárias ações de educação em saúde, como o círculo de cultura, que propiciam ao jovem expor suas dúvidas e conhecer os meios de prevenção, capacitando-os a repensar condutas, favorecendo uma melhor qualidade de vida.

\section{Colaboradores}

EP Beserra, PN C Pinheiro, M DS Alves e M GT Barroso trabalharam na concepção teórica, elaboração e redação final do texto; CA Torres participou da organização e execução das oficinas e da revisão bibliográfica. 


\section{Referências}

1. Catrib AM F, Pordeus AMJ, Ataíde MBC, Albuquerque VLM, Vieira NFC. Promoção da saúde: saber fazer em construção. In: Barroso M GT, Vieira NFC, Varela ZM V, organizadores. Educação em saúde: no contexto da promoção humana. Fortaleza: Demócrito Rocha; 2003.

2. Zagury T. 0 adolescente por ele mesmo. $11^{\text {a }}$ ed. Rio de Janeiro: Record; 2000.

3. Brasil. Ministério da Saúde. Secretaria de Vigilância em Saúde. Programa Nacional de DST e Aids. Boletim Epidemiológico - Aids e DST 2006; 3(1).

4. Rieth F. A iniciação sexual na juventude de mulhe res e homens. Horiz. antropol. 2002; 17(8):77-91.

5. Beserra EP, Araújo M FM, Barroso M GT. Promo ção da saúde em doenças transmissíveis - uma investigação em adolescentes. Acta Paul Enferm 2006; 9(4):402-407.

6. Brandão CR.O que é método Paulo Freire. $25^{\mathrm{a}} \mathrm{ed}$. São Paulo: Brasiliense; 2004.

7. Bardin L. Análise de conteúdo. Lisboa: Edições 70; 1977.

8. Heidemann M. Adolescência e saúde: uma visão pre ventiva: para profissionais de saúde e educação. Pe trópolis: Vozes; 2006.

9. Taquette SR, Vilhena M M, Paula MC. Doenças se xualmente transmissíveis e gênero: um estudo transversal com adolescentes no Rio de Janeiro. Cad Saude Publica 2004; 20(1):282-290.

10. Borges ALV, Nichiata LYI, Schor N. Conversando sobre sexo: a rede sociofamiliar como base de promoção da saúde sexual e reprodutiva de adolescentes. Rev. Latino-Am. Enfermagem 2006; 14(3):422-427.

11. Freire P. Ação cultural para a liberdade e outros escritores. 10åed. São Paulo: Paz e Terra; 2002.
12. Carvalho ALS, Bezerra SJS, Leitão NM A, Joca MT, Pinheiro AKB. Porte, acondicionamento e utilização de preservativo masculino entre jovens de Fortaleza - um estudo descritivo. Online braz. j. nurs. [periódico na Internet] 2007 [acessado 2006 dez 02] 6(0). Disponível em: http://www.uff.br/objnursing/ index.php/nursing/rt/printerFriendly/566/130

13. Geluda K, Bosi MLM, Cunha AJLA, Trajman A. "Quando um não quer, dois não brigam": um estudo sobre o não uso constante de preservativo masculino por adolescentes do Município do Rio de Janeiro, Brasil. Cad Saude Publica 2006; 22(8):16711680

14. Silva CGM . 0 significado de fidelidade e as estraté gias para prevenção da Aids entre homens casados. Rev. Saude Publica 2002; 36(4):40-49.

15. Almeida MCC, Aquino EM L, Gaffikin L, Magnani RJ. Uso de contracepção por adolescentes de escolas públicas na Bahia. Rev. Saude Publica 2003; 37(5):566-575.

16. Martins LB, Costa-Paiva M L, Osis M JD, Sousa MH, Pinto Neto AM, Tadini V. Conhecimento sobre métodos anticoncepcionais por estudantes adolescentes. Rev. Saude Publica 2006; 40(1):57-64.

Artigo apresentado em 17/04/2008

Aprovado em 31/10/2008

Versão final apresentada em 12/11/2008 